\title{
The Technological Enhancement of Normally Occurring Radioactive Materials in Red Mud due to the Production of Alumina
}

\author{
Maurice O. Miller ${ }^{1}$ and Dionne A. Miller ${ }^{2}$ \\ ${ }^{1}$ The University of the West Indies, Mona Campus, Kingston 6, Jamaica \\ ${ }^{2}$ LaGuardia Community College, 31-10 Thomson Avenue, Long Island City, NY 11101, USA \\ Correspondence should be addressed to Maurice O. Miller; moneilmiller@gmail.com
}

Received 9 November 2015; Revised 7 February 2016; Accepted 9 February 2016

Academic Editor: Craig J. Eckhardt

Copyright (C) 2016 M. O. Miller and D. A. Miller. This is an open access article distributed under the Creative Commons Attribution License, which permits unrestricted use, distribution, and reproduction in any medium, provided the original work is properly cited.

This study investigates the level of technological enhancement of normally occurring radioactive materials (TENORM) in the red mud waste due to the production of alumina in Jamaica. Technological enhancements factors (TEF) were determined for the uranium, thorium, actinium series, their progenies, and the nonseries potassium-40 using gamma spectrometry. The study concluded that bauxite production technologically enhances the uranium progenies $\mathrm{Th}-234, \mathrm{~Pb}-214, \mathrm{Bi}-214$, and $\mathrm{Pa}-234$ and the thorium-232 progenies Ac-228, $\mathrm{Pb}-212$, and $\mathrm{Bi}-212$ in red mud. The actinium series was technologically enhanced, but $\mathrm{K}-40$ and the thorium daughter, Tl-208, were reduced. The spectrometric comparison of Tl-208 (at $510 \mathrm{keV}$ ) was unexpected since its other photopeaks at $583 \mathrm{keV}, 934 \mathrm{keV}$, and $968 \mathrm{keV}$ were markedly different. An explanation for this anomaly is discussed. An explanation regarding the process of accumulation and fractionation of organically derived phosphate deposits and potassium-feldspar is offered to explain the spectrometric differences between the alumina product and its waste material, red mud.

\section{Overview}

Bauxite is the geological result of plate tectonics and climatic conditions occurring over a period of approximately 500 million years [1]. The impact and radioecological significance of bauxite in the environment have been studied [2-8]. Other studies have examined the mineralogy of bauxite deposits in Jamaica and in Nigeria. The NORM and dose assessment in the bauxite industry has been analyzed $[9,10]$. In China, analysis of the levels of radioactivity in the red mud and red mud cement and its dose rate for local residents demonstrate the level of interest in this area [11]. Gibbsitic bauxite with a mineralogical composition $\mathrm{Al}(\mathrm{OH})_{3}$ is the most predominant and geologically youngest type of bauxite. It is found in tropical or subtropical regions such as Jamaica and located very close to the ground surface. Jamaican bauxite is about $80 \%$ gibbsitic $\left(\alpha-\mathrm{Al}_{2} \mathrm{O}_{3} \cdot 3 \mathrm{H}_{2} \mathrm{O}\right)$ but some amount of boehmite, $\alpha$ $\mathrm{Al}_{2} \mathrm{O}_{3} \cdot \mathrm{H}_{2} \mathrm{O}$ (up to $20 \%$ in some instances), is also present ( $\alpha$ $=90)[9,12]$. The most abundant minerals associated with the deposits are iron oxide, kaolinite $\mathrm{Al}_{2} \mathrm{Si}_{2} \mathrm{O}_{5}(\mathrm{OH})_{4}$, and quartz.
Results (from X-ray diffraction, differential thermal analysis, electron, and optical microscope) indicate that the White Limestone is the source of the Jamaican ore. In this study the main constituents were determined to be $\mathrm{Al}_{2} \mathrm{O}_{3}(45-52 \%)$, $\mathrm{Fe}_{2} \mathrm{O}_{3}(15-25 \%), \mathrm{SiO}_{2}(0.1-10 \%), \mathrm{TiO}_{2}(2.0-2.6 \%), \mathrm{P}_{2} \mathrm{O}_{5}(0.1-$ $5.0 \%$ ), and water (18.0-25.0\%) [9]. In Jamaica, approximately ten million tons of bauxite and alumina has been mined each year since 2011. At the height of its production, over 14 million tons per year was produced between 2005 and 2008 [13]. It is estimated that 4 million tons of bauxite waste per year is produced locally and 70 million tons per year worldwide [14]. In Jamaica, this red mud waste is distributed over six locations covering a total of 650 hectares $(\mathrm{Ha})$. Bauxite ore is processed by mixing dried bauxite with hot caustic solutions to dissolve the alumina from the bauxite. The chemical composition of red mud varies but in general is comprised as follows: $\mathrm{Al}_{2} \mathrm{O}_{3}(10-25 \%), \mathrm{Na}_{2} \mathrm{O}(2-10 \%), \mathrm{SiO}_{2}$ (3-50\%), $\mathrm{Fe}_{2} \mathrm{O}_{3}$ (30-60\%), $\mathrm{TiO}_{2}(1-10 \%)$, and $\mathrm{CaO}(1-8 \%)$ [15]. Bauxite refineries produce alumina $\left(\mathrm{Al}_{2} \mathrm{O}_{3}\right)$ which is used primarily as a feedstock for the aluminum production 
industry. The bauxite residue, called "red mud," is removed in settling tanks and placed in a tailings impoundment near the plant. In some plants, red mud is further processed to produce aluminum oxides. The waste product from this process is called "brown mud." The refinery muds (both red and brown mud) dry to a solid with very fine particle size (about $1 \mu \mathrm{m}$ ) and contain significant amounts of iron, aluminum, calcium, and sodium. They may also contain trace amounts of TENORM and various elements, such as barium, boron, cadmium, chromium, cobalt, gallium, lead, scandium, and vanadium. The types and concentrations of minerals present in the muds depend on the composition of the ore and processing conditions [16]. NORM wastes are the radioactive residues from anthropogenic mining sources such as uranium, fertilizer, copper, gold, silver, rare earth metals, titanium, zircon, and aluminum. These products and their waste may contain varying elevated concentrations of primordial radionuclides depending on the activity and the materials being processed. It is estimated that each year hundreds of millions of metric tons of NORM waste is generated from a wide variety of processes, ranging from uranium and phosphate mining to municipal drinking water treatment [16].

According to the United States Environmental Protection Agency, technologically enhanced naturally occurring radioactive material (TENORM) is produced from anthropological sources such as uranium mining or sewage sludge treatment. These activities concentrate or expose radioactive materials that occur naturally in ores, soils, water, or other natural materials. Naturally occurring radioactive material (NORM) consists primarily of material containing potassium-40 and isotopes belonging to the primordial series. The most environmentally important primordial radionuclides are the radioactive isotopes uranium238 (uranium series), uranium-235 (actinium series), and thorium-232 (thorium series). All three series have very long half-lives and numerous radionuclides in their decay chains before reaching a stable end point, lead $(\mathrm{Pb})$. Along with $\mathrm{K}$ 40 , these three series are important because at background concentrations, they contribute about half of the natural background external radiation. They also account for over 80 percent of the background including radon, to which all humans are continuously exposed.

This study examines and quantifies the technological enhancement in the progenies of the thorium, actinium, and uranium series, and the nonseries potassium-40 in red mud due to alumina production in Jamaica. The rationale for the results is also discussed.

\section{Methods and Materials}

The detector used in this research was a Canberra 3825 HPGe detector (absolute efficiency $=27.61$ percent, measured, and 28.15 percent, ISOCS value). This detector has an active area of $38 \mathrm{~cm}^{2}$ and active diameter of $71 \mathrm{~mm}$ and was cryogenically cooled by liquid nitrogen in a vertical dipstick type 7500SL 30 litres Dewar throughout the measurement process. The detector and samples were enclosed in a Canberra Model
$747 \mathrm{E}$ lead shield. The $10 \mathrm{~cm}$ thick shield weighted $950 \mathrm{~kg}$ and was graded with $1 \mathrm{~mm}$ tin and $1.6 \mathrm{~mm}$ copper liner to reduce interference from lead X-rays, cosmic and background radiation. This construction reduced counting time and improved the lower levels of detection during photopeak counting [17]. Canberra's Genie 2000 Gamma Acquisition and Analysis software (Ver 3.2.1) was used in the spectra capturing process. All spectra were energy corrected using the program Energy Correction (ENERCOR). The overlapping photopeaks at $185 \mathrm{keV}$ (Ra-226 and U-235) and $241 \mathrm{keV}$ (Ra-224 and Pb212) were resolved using a program called SPLIT. Summing corrections were made using a software for correcting summing effect called \$RSUMUP. The data to which the summing corrections were applied was provided by a software called Efficiency Transfer (EFTRAN). EFTRAN, an efficiency transfer correction utility for environmental gamma-ray spectrometry, was provided by Tim Vidmar of the Belgian Nuclear Research Centre. All spectra were analyzed using a gamma spectrum analytical software called SPECTRW. The spectrometric results and reports were produced with gamma utilities named ANALYSIS (for data analysis) and ISO-REPT (a utility for producing the analytical reports), respectively. SPECTRW, \$RSUMUP, ISO-REPT, SPLIT, and ENERCOR were developed by Costas Kalfas, Demokritos, Greece. The spectrometric data were converted to $\mathrm{Bq} / \mathrm{kg}$, and all data were reported with their corresponding errors to at least 3 significant figures.

\section{Results and Discussion}

Figure 1 shows combined spectra for alumina and its red mud waste over the energy range up to $2 \mathrm{MeV}$. The spectrum in red is for red mud and the blue one is for alumina. The diagram shows well-defined photopeaks due to the high resolution of the detector used in this study. For the alumina spectrum, the full width half maximum (FWHM) of the photopeaks ranged from 0.62 to $2.36 \mathrm{keV}$. Similarly high resolutions were recorded in the red mud waste (0.67 to 2.67) where 42 photopeaks were identified. Generally, errors in the net count of the photopeaks were as low as $0.9 \%$ for peaks with high net counts (up to 20,994) and $8.3 \%$ for peaks with low net counts $(<500)$. The activity of uranium series was deduced from the activities of $\mathrm{U}-238$ progenies $\mathrm{Ra}-226, \mathrm{~Pb}-214$, Th234, $\mathrm{Pa}-234$, and $\mathrm{Bi}-214$. For the thorium series, the activity was determined from the activities of the Th-232 progenies Tl-208, Ac-228, Pb-212, and Bi-212. The actinium series was determined from the analysis of U-235 keV5 at $185.71 \mathrm{keV}$ following its resolution from the spectral interfering $\mathrm{Ra}-226$ photopeak.

Closer spectral comparison for various energy ranges is shown in Figures 2-6. It is observed that all the major progenies in the uranium, thorium, and actinium series are technologically enhanced in the red mud waste (Figures 2-4 and 6). The opposite is noted with potassium-40, where its value decreases in the red mud (Figure 5). From the calculated specific activities, actinium-228 (Ac-228), protactinium-234 (Pa-234), lead-212 (Pb-212), and bismuth-212 were determined to be below the MDA in the Jamaican alumina sample. 


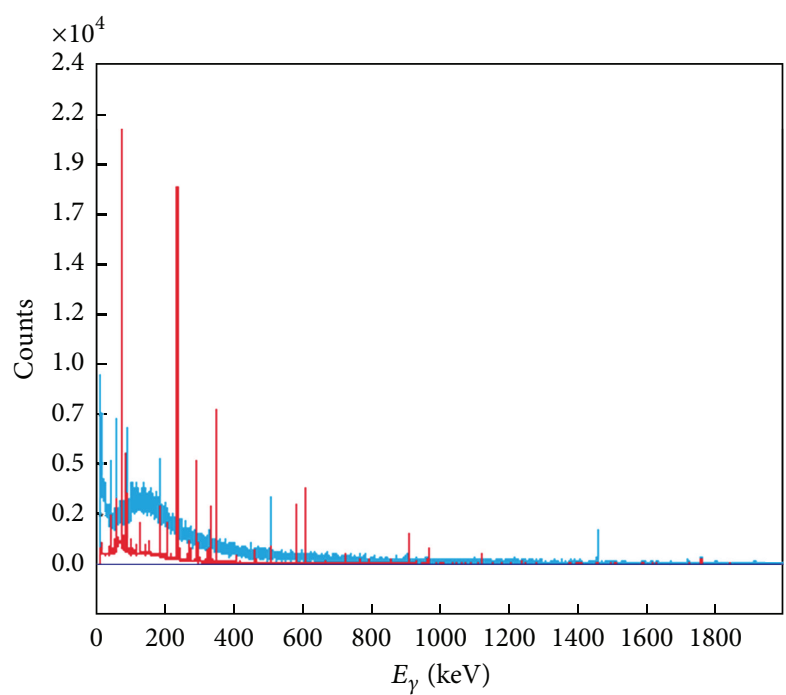

FIGURE 1: Spectral comparison in the gamma energy range up to $2 \mathrm{MeV}$ showing the photopeaks in red mud (red spectrum) and alumina (blue spectrum) after the background was subtracted. All samples were counted for 24 hours. Counts on the vertical axis are in $10^{4}$.

Although the thorium series was technologically enhanced in red mud, the photopeak for its progeny, Tl-208 at $510.77 \mathrm{keV}$, was higher in alumina $(1298.5 \pm 29.0) \mathrm{Bq} / \mathrm{kg}$ than in its red mud waste $(289.07 \pm 5.67) \mathrm{Bq} / \mathrm{kg}$ by a factor of 5 . Its other photopeaks at $583 \mathrm{keV}$ (Figure 3) and $964 \mathrm{keV}$ (Figure 4) have reverse comparative values. It should be noted however that spectral interference due to the gamma pair production process occurs in the vicinity of $510 \mathrm{keV}$ and may therefore account for this anomalous result. For this reason, this photopeak is generally disregarded in gamma spectrometry.

Although U-238 was technologically enhanced by a factor of 3.86 in alumina (Table 1), the enhancement of its progeny Bi-214 at $1764 \mathrm{keV}$ (Figure 6) was less significant. The comparative specific activities at this energy were $239.84 \pm$ $8.13 \mathrm{~Bq} / \mathrm{kg}$ and $350.50 \pm 10.76 \mathrm{~Bq} / \mathrm{kg}$ for alumina and red mud, respectively, a TEF of 1.46 . The study concludes that the lower energy peaks of the U-238 progenies $(<1200 \mathrm{keV})$ have a greater impact in the technological enhancement data.

Figure 7 shows the specific activity $(\mathrm{Bq} / \mathrm{kg})$ of the nonseries potassium-40, actinium, uranium, and thorium series in red mud and alumina in Jamaica. The levels of technological enhancements in the red mud waste compared to the alumina are shown in Table 1.

With the exception of potassium-40 (K-40), the specific activities in all the primordial series (actinium, thorium, and uranium) were all enhanced in the red mud lakes. The results suggest that the accumulation of K-40 in alumina is dominant in the Bayer process, while uranium, actinium, and thorium accumulates in the red mud. The Bayer process is the industrial means of refining bauxite to produce alumina (aluminum oxide). The potassium is likely found in potassiumfeldspar, as there is no other evidence for other potassium salts/compounds in Jamaican bauxite [9]. The higher levels of K-40 in alumina indicate that the potassium-feldspar

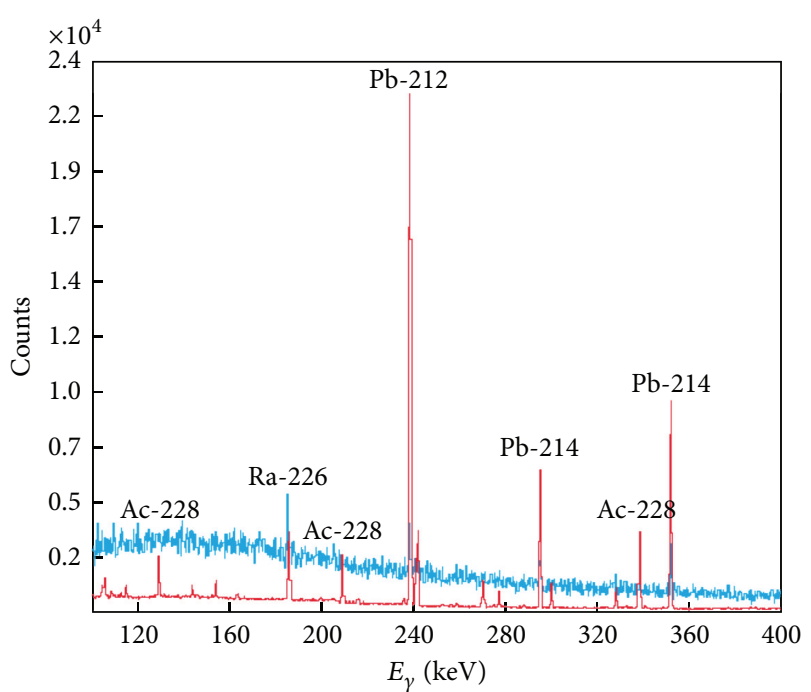

FIGURE 2: Comparison in the gamma energy range 120 to $380 \mathrm{keV}$ showing the photopeaks for Ac-228 (128.7 keV), composite U235 and Ra-226 (185.71 keV and $186.21 \mathrm{keV}), \mathrm{Ac}-228(209.39 \mathrm{keV})$, composite Ra-224 and Pb-212 (241 keV and $241.91 \mathrm{keV}), \mathrm{Pb}-214$ (295.17 keV), Ac-228 (338.42 keV), and Pb-214 (351.9 keV) in red mud (red spectrum) and alumina (blue spectrum). Counts on vertical axis are in $10^{4}$.

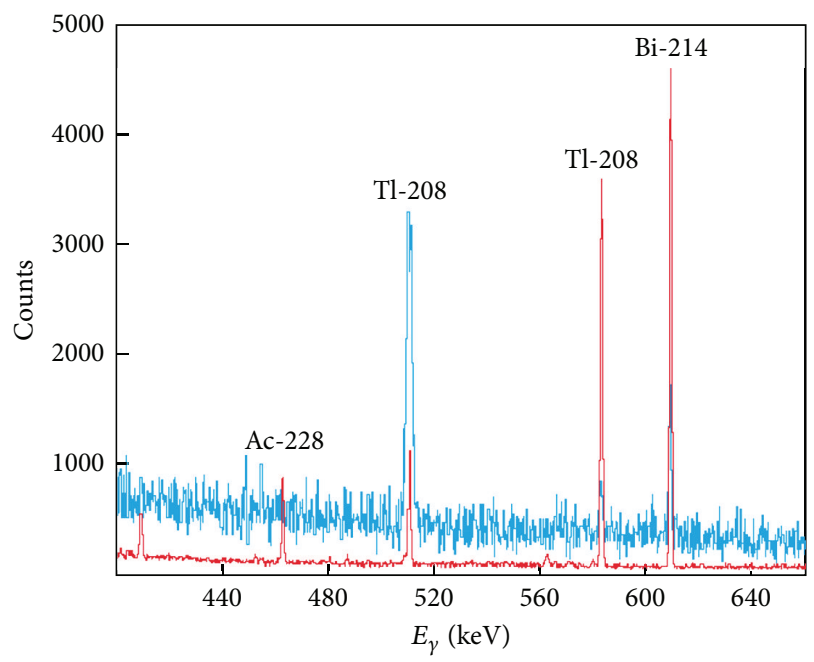

FIGURE 3: Comparison in the gamma energy range 480 to $640 \mathrm{keV}$ showing the photopeaks for Ac-228 (463.1 keV), Tl-208 (510.77 keV), Tl-208 (583.19 keV), and Bi-214 $(609.32 \mathrm{keV})$ in red mud (red spectrum) and alumina (blue spectrum).

$\left(\mathrm{KAlSi}_{3} \mathrm{O}_{8}\right.$ ) in the soil is more strongly bounded to alumina than the other mineral elements in the red mud. Another likely explanation is that K-feldspar (containing K-40 among other isotopes) is also soluble in the caustic solution used to dissolve alumina and coprecipitates with the alumina. In Jamaica, the high levels of U-238 are associated with concentrations in organically derived phosphate deposits. The higher concentration of this radionuclide in the red mud suggests an increased concentration following the removal of alumina from the bauxite ore. It is quite probable that the calcination 
TABLE 1: Technological enhancement factor (TEF) in red mud. The TEF in red mud in this study is determined by the ratio of the specific activity $(\mathrm{Bq} / \mathrm{kg})$ of the primordial in red mud to the specific activity in alumina. MDA refers to the "minimum detectable activity" of the detector used in this study.

\begin{tabular}{lccc}
\hline Primordial/specific activity & Alumina $(\mathrm{Bq} / \mathrm{kg})$ & Red mud $(\mathrm{Bq} / \mathrm{kg})$ & Technological enhancement factor $(\mathrm{TEF})$ in red mud \\
\hline K-40 & $1130.9 \pm 27.6$ & $79.200 \pm 3.336$ & 0.07 (reduction) \\
U-238 & $69.46 \pm 3.10$ & $268.31 \pm 4.71$ & 3.86 \\
Th-232 & Below MDA & $326.08 \pm 5.33$ & High and undefined \\
U-235 & $10.075 \pm 0.405$ & $16.153 \pm 1.006$ & 1.60 \\
\hline
\end{tabular}

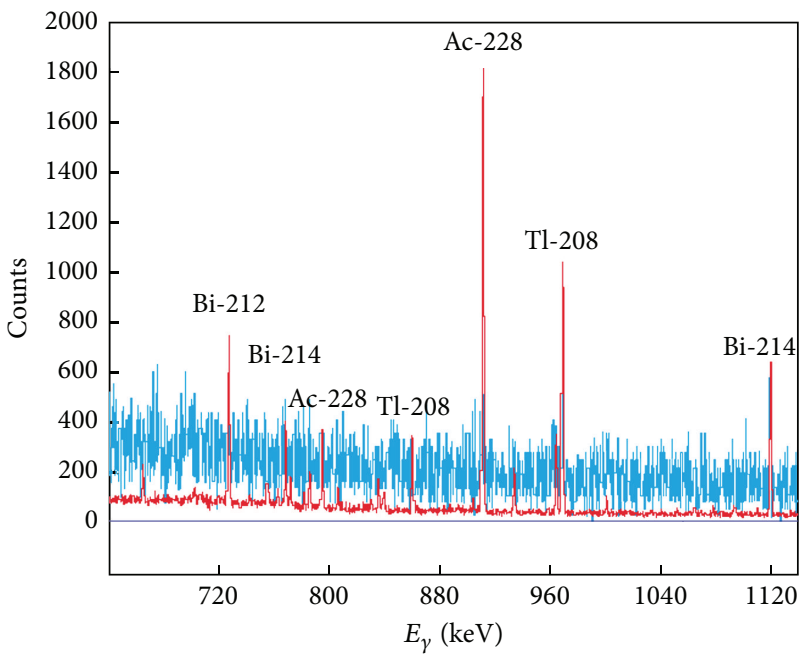

Figure 4: Comparison in the gamma energy range 640 to $1120 \mathrm{keV}$ showing the photopeaks for Bi-212 (727.33 keV), Bi-214 (768.36), Ac$228(794.79 \mathrm{keV}), \mathrm{Tl}-208(860.56 \mathrm{keV})$, Ac-228 (911.16 keV), Ac-228 (964.64 kev and $968.97 \mathrm{keV})$, and Bi-214 (1120.27 keV) in red mud (red spectrum) and alumina (blue spectrum).

process where gibbsitic bauxite is heated to approximately $1100^{\circ} \mathrm{C}$ to remove chemically combined water (to produce alumina) concentrates the phosphate deposits in the red mud. Another heat-related process is the digestion process which relies on the solubility of amphoteric aluminum oxides to form a solution of aluminate ions. This chemical process occurs at between 135 and $150^{\circ} \mathrm{C}$ for the predominant bauxite gibbsite found in Jamaica:

$$
\mathrm{Al}_{2} \mathrm{O}_{3} \cdot 3 \mathrm{H}_{2} \mathrm{O}+2 \mathrm{NaOH} \longrightarrow 2 \mathrm{NaAlO}_{2}+4 \mathrm{H}_{2} \mathrm{O}\left(135-150^{\circ} \mathrm{C}\right)
$$

This process would also impact water-soluble radionuclides.

The accumulations noted in the red mud are problematic from the perspective of exposure to humans. The fractionation process in potassium-40 is also problematic. Miller and Voutchkov and other researchers have noted that Cs-137 and K-40 are negatively correlated in the soil environment [18]. This is demonstrated in this study, where Cs-137 with an activity of $328.92 \pm 20.18 \mathrm{~Bq} / \mathrm{kg}$ was detected in the red mud, but not in its alumina product. Figure 8 and Table 2 show the detailed comparisons of the major progenies of the uranium, thorium, and the actinium series investigated in this study.

From the technological enhancement factor (TEF) in Table 2, the study concludes that the bauxite production technologically significantly enhances the uranium progenies

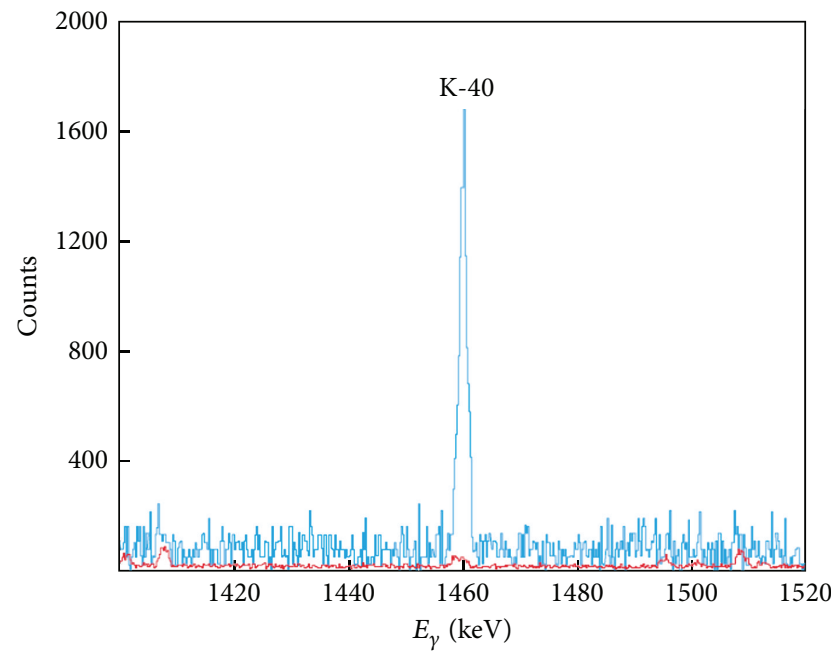

FIGURE 5: Comparison showing the reduction of K-40 photopeak $(1460.83 \mathrm{keV})$ in alumina (blue spectrum) compared to red mud (red spectrum).

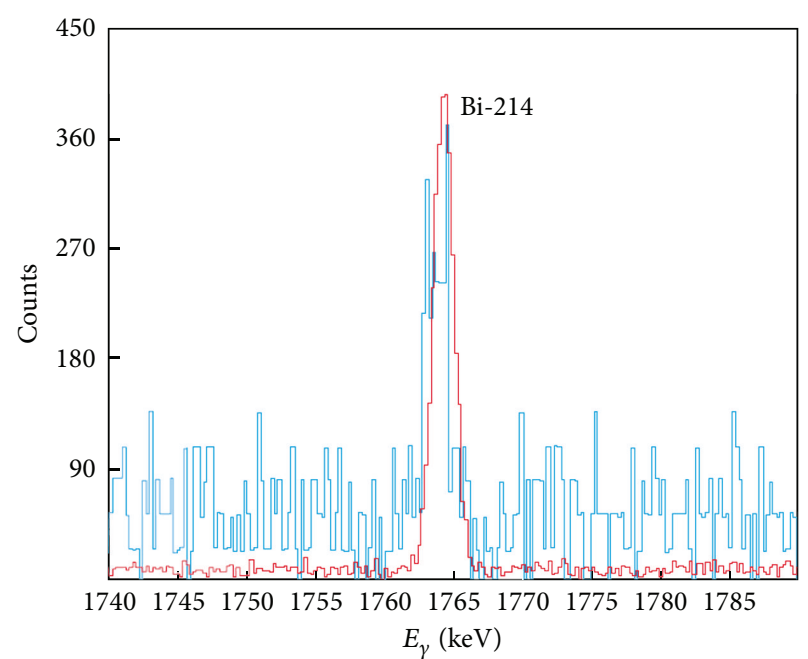

FIgURE 6: Comparison showing the photopeaks for Bi-214 $(1764 \mathrm{keV})$ in red mud (red spectrum) and alumina (blue spectrum).

Th-234 and Pa-234 and the thorium-232 progenies Ac-228 and $\mathrm{Bi}-212$ in red mud, while reducing $\mathrm{K}-40$ and $\mathrm{Tl}-208$. 
TABLE 2: The technological enhancement in the specific activity $(\mathrm{bq} / \mathrm{kg})$ of the progenies of the primordial radionuclides series in red mud due to the production of alumina in Jamaica.

\begin{tabular}{|c|c|c|c|}
\hline Progenies and K-40 (primordial series) & $\begin{array}{l}\text { Alumina }(\mathrm{Bq} / \mathrm{kg}) \\
\mathrm{Bq} / \mathrm{kg}\end{array}$ & $\begin{array}{c}\text { Red mud }(\mathrm{Bq} / \mathrm{kg}) \\
\mathrm{Bq} / \mathrm{kg}\end{array}$ & Technological enhancement factor (TEF) in red mud \\
\hline $\mathrm{K}-40$ & $1130.9 \pm 27.6$ & $79.200 \pm 3.336$ & 0.07 \\
\hline Th-234 & $316.21 \pm 8.01$ & $345.54 \pm 10.24$ & 1.09 \\
\hline $\mathrm{Pa}-234$ & Below MDA & $341.10 \pm 6.90$ & Positive and undetermined \\
\hline $\mathrm{Ra}-226$ & $218.04 \pm 8.73$ & $341.10 \pm 6.90$ & 1.56 \\
\hline $\mathrm{Pb}-214$ & $48.060 \pm 1.503$ & $293.43 \pm 13.29$ & 6.10 \\
\hline $\mathrm{Bi}-214$ & $111.49 \pm 3.38$ & $292.73 \pm 13.50$ & 2.62 \\
\hline $\mathrm{Pa}-234$ & Below MDA & $156.92 \pm 6.62$ & Positive and undetermined \\
\hline Ac-228 & Below MDA & $326.84 \pm 5.46$ & Positive and undetermined \\
\hline $\mathrm{Pb}-212$ & Below MDA & $353.16 \pm 5.14$ & Positive and undetermined \\
\hline $\mathrm{Bi}-212$ & Below MDA & $363.04 \pm 19.15$ & Positive and undetermined \\
\hline Tl-208 & $1298.5 \pm 29.0$ & $289.07 \pm 5.67$ & 0.22 \\
\hline $\mathrm{U}-235$ & $10.075 \pm 0.405$ & $16.153 \pm 1.006$ & 1.60 \\
\hline
\end{tabular}

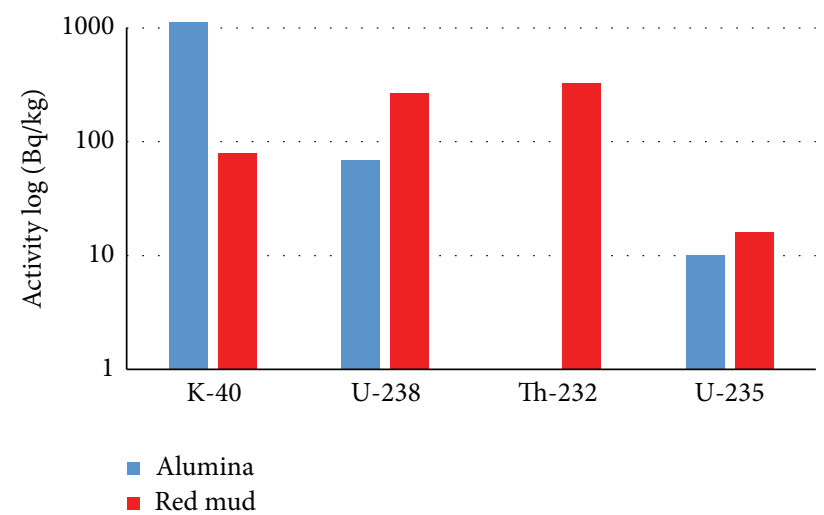

Figure 7: The figure shows the specific activity $(\mathrm{Bq} / \mathrm{kg})$ of the nonseries potassium-40, actinium, uranium, and thorium series in red mud and alumina in Jamaica. The levels of technological enhancements in the red mud waste compared to the alumina are shown in Table 1.

\section{Conclusion}

This study confirms and quantifies technologically enhanced normally occurring radioactive material (TENORM) process in the production of alumina from bauxite mining in Jamaica. The data suggest that significant accumulation of K- 40 occurs in alumina by the production process, resulting in very low levels of the radionuclide in the red mud waste product. The specific activity of K-40 in alumina $(1234 \mathrm{~Bq} / \mathrm{kg})$ is higher by a factor of six (6) than the mean soil value $(\mathrm{M}=200.76 \pm 21.50, \mathrm{SD}=177.33)$ reported by Miller and Voutchkov [18]. The spectrometric comparison of Tl208 (at $510 \mathrm{keV})$ is unexpected since its other photopeaks at $583 \mathrm{keV}$ (Figure 3), $934 \mathrm{keV}$, and $968 \mathrm{keV}$ (Figure 4) are markedly different. A possible explanation for this anomaly is that spectral interference, due to the pair production process, was more significant in alumina than in red mud. Due to the elevation of U-238 and Th-232, and the reduction of K-40, the study disagrees with a recommendation from the United

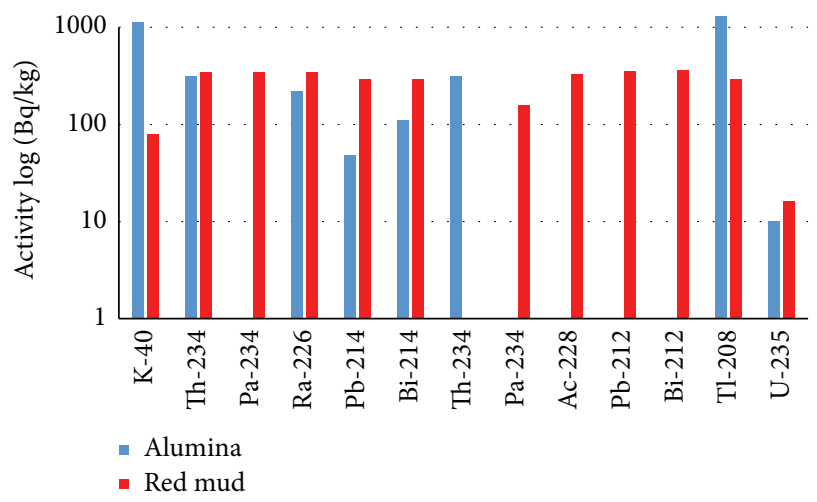

FIGURE 8: Logarithmic graph showing the specific activity $(\mathrm{bq} / \mathrm{kg})$ of the progenies of the primordial radionuclides series in red mud and alumina due to the production of alumina in Jamaica.

States Environmental Protection Agency (US EPA) that this waste can be used in land reclamation [19].

\section{Conflict of Interests}

The authors declare that there is no conflict of interests regarding the publication of this paper.

\section{References}

[1] Alteo, "Bauxite extraction," 2015, http://www.alteo-alumina .com/en/bauxite-extraction.

[2] G. C. Lalor, "Review of cadmium transfers from soil to humans and its health effects and Jamaican environment," Science of the Total Environment, vol. 400, no. 1-3, pp. 162-172, 2008.

[3] W. R. Pinnock, "Radon levels and related doses in a prototype Jamaican house constructed with bauxite waste blocks," Radiation Protection Dosimetry, vol. 81, no. 4, pp. 291-299, 1999.

[4] M. Ndontchueng, E. Nguelem, O. Motapon et al., "Radiological hazards in soil from the bauxite deposits sites in dschang region 
of cameroon," British Journal of Applied Science \& Technology, vol. 5, no. 4, pp. 342-352, 2015.

[5] K. J. Summers, B. H. O'Connor, and D. R. Fox, "Radiological consequences of amending soils with bauxite residue/gypsum mixtures," Australian Journal of Soil Research, vol. 31, no. 4, pp. 533-538, 1993.

[6] R. G. Garrett, A. R. D. Porter, and P. A. Hunt, "An occurrence of cadmiferous phosphorite soil concretions in Jamaica," Applied Geochemistry, vol. 25, no. 7, pp. 1047-1055, 2010.

[7] W. R. Pinnock, "Measurements of radioactivity in Jamaican building materials and gamma dose equivalents in a prototype red mud house," Health Physics, vol. 61, no. 5, pp. 647-651, 1991.

[8] M. B. Cooper, P. C. Clarke, W. Robertson, I. R. McPharlin, and R. C. Jeffrey, "An investigation of radionuclide uptake into food crops grown in soils treated with bauxite mining residues," Journal of Radioanalytical and Nuclear Chemistry, vol. 194, no. 2, pp. 379-387, 1995.

[9] V. G. Hill, "The mineralogy and genesis of the bauxite deposits of Jamaica, B.W.I.," American Mineral, vol. 40, pp. 676-688, 1995.

[10] J. A. Ademola and M. A. Olatunji, "Evaluation of NORM and dose assessment in an aluminium industry in Nigeria," World Journal of Nuclear Science and Technology, vol. 3, no. 4, pp. 150154, 2013.

[11] K. Wang, "Levels of radioactivity in the red mud and red mud cement and its dose rate for local residents," Huanjing Kexue, vol. 13, pp. 90-93, 1992.

[12] R. Lanchashire, Bauxite and Alumina Production, Education in Chemistry, 1982.

[13] Jamaica Bauxite Institute (JBI), 2015, http://jbi.org.jm/pages/ lands.

[14] S. Persaud, Waste from the Bauxite and Alumina Industry, Jamaica Bauxite Institute, Kingston, Jamaica, 2013.

[15] Laboratory of Metallurgy, University of Patras, and Aluminium de Grece, "The International Commitee for Study of Bauxite AA," Red Mud Project, July 2015, http://redmud.org.

[16] U.S. Environmental Protection Agency, TechnologicallyEnhanced, Naturally-Occurring Radioactive Materials, EPA, 2015.

[17] Canberra, Canberra Application Note-Low Background Detector System, 2013, http://www.canberra.com/fr/produits/detectors/pdf/Low-BkgDet-Introduction.pdf.

[18] M. Miller and M. Voutchkov, "Evaluation of gamma activities of naturally occurring radioactive materials in uncontaminated surface soils of Jamaica," Journal of Radioanalytical and Nuclear Chemistry, vol. 300, no. 1, pp. 303-313, 2014.

[19] USEPA Aluminum Production Wastes, 2015, http://www.epa .gov/radiation/tenorm/aluminum.html. 

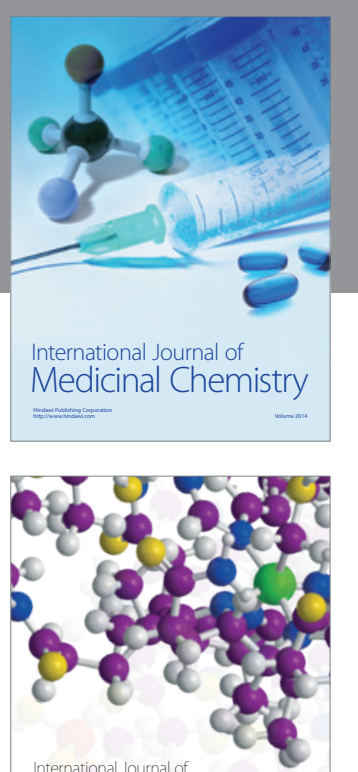

Carbohydrate Chemistry

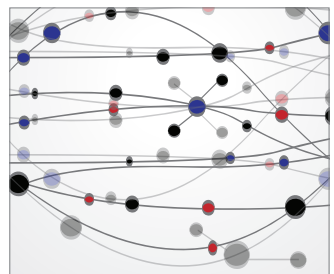

The Scientific World Journal
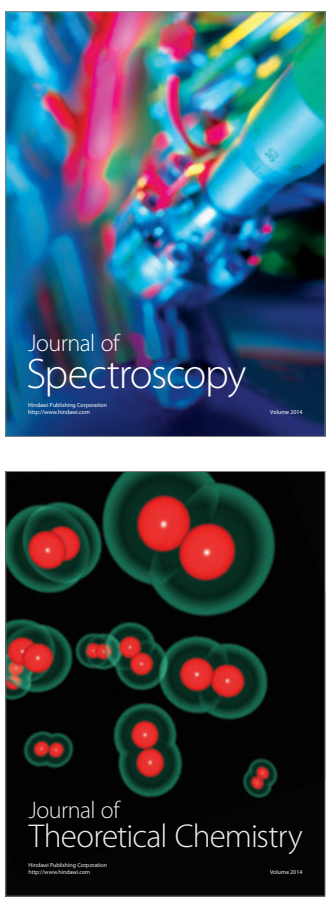
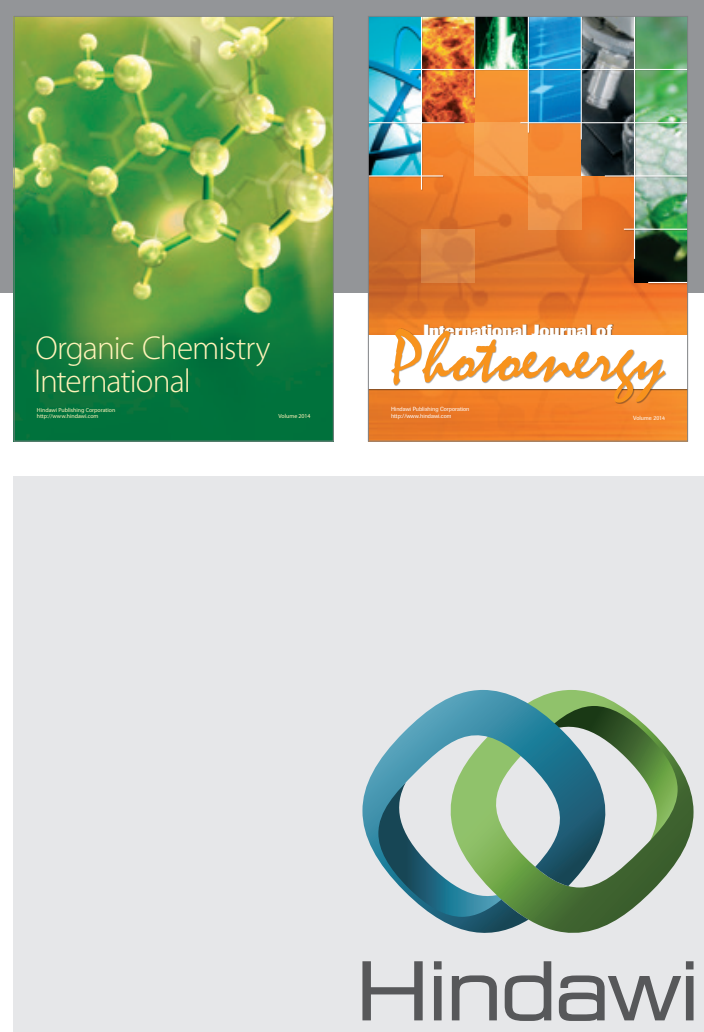

Submit your manuscripts at

http://www.hindawi.com

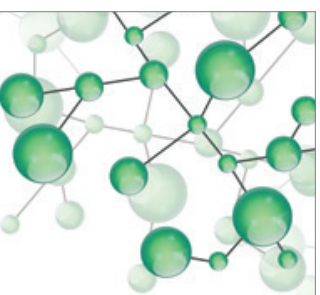

International Journal of

Inorganic Chemistry

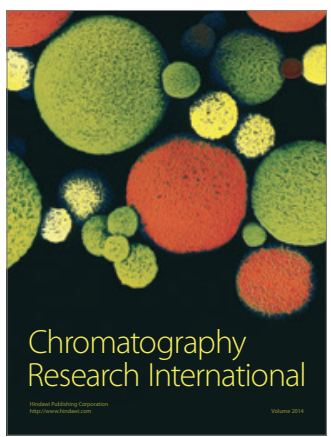

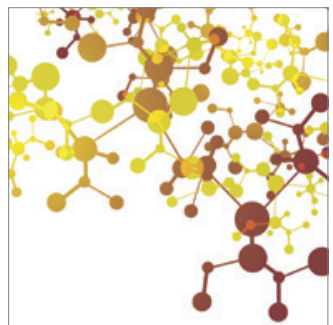

Applied Chemistry
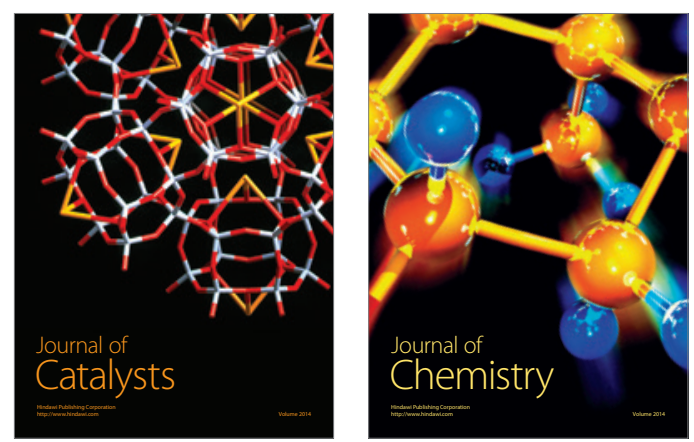
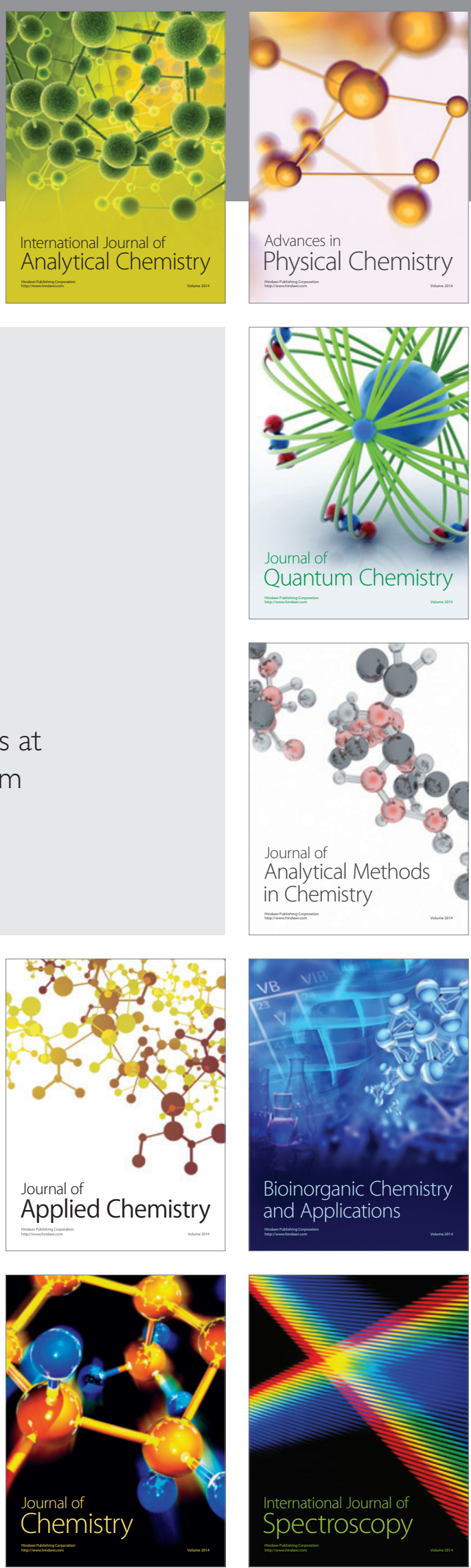